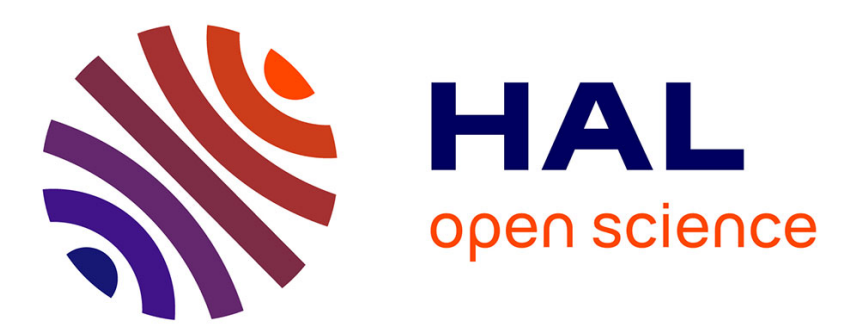

\title{
Crack growth measurement and J-integral evaluation of additively manufactured polymer using digital image correlation and FE modeling
}

Mohamed Ali Bouaziz, Joseph Marae Djouda, Marouene Zouaoui, Julien Gardan, François Hild

\section{To cite this version:}

Mohamed Ali Bouaziz, Joseph Marae Djouda, Marouene Zouaoui, Julien Gardan, François Hild. Crack growth measurement and J-integral evaluation of additively manufactured polymer using digital image correlation and FE modeling. Fatigue and Fracture of Engineering Materials and Structures, 2021, 44, pp.1318-1335. 10.1111/ffe.13431 . hal-03118861

\section{HAL Id: hal-03118861 \\ https://hal.science/hal-03118861}

Submitted on 22 Jan 2021

HAL is a multi-disciplinary open access archive for the deposit and dissemination of scientific research documents, whether they are published or not. The documents may come from teaching and research institutions in France or abroad, or from public or private research centers.
L'archive ouverte pluridisciplinaire HAL, est destinée au dépôt et à la diffusion de documents scientifiques de niveau recherche, publiés ou non, émanant des établissements d'enseignement et de recherche français ou étrangers, des laboratoires publics ou privés. 


\title{
Crack growth measurement and $J$-integral evaluation of additively manufactured polymer using digital image correlation and FE modeling
}

\author{
Mohamed Ali BOUAZIZ ${ }^{1}$, Joseph MARAE DJOUDA ${ }^{1-2}$, Marouene ZOUAOUI ${ }^{1-3}$, \\ Julien GARDAN ${ }^{1-3}$, François HILD ${ }^{2}$
}

\begin{abstract}
${ }^{1}$ ERMESS, EPF-Engineering school, 3 bis rue Lakanal, 92330 Sceaux, France
${ }^{2}$ Université Paris-Saclay, ENS Paris-Saclay, CNRS, LMT - Laboratoire de Mécanique et Technologie, 4 avenue des sciences, 91190 Gif-sur-Yvette, France

${ }^{3}$ Institut Charles Delaunay, LASMIS, UTT, UMR CNRS 6281, 12 rue Marie Curie, 10010 Troyes, France
\end{abstract}

\begin{abstract}
This paper presents and compares two combined experimental-numerical techniques for the investigation of fracture properties of additively manufactured polymer parts using digital image correlation (DIC) measurements. The first method only uses measured kinematic fields, and the second is based on Finite Element simulations driven by measured boundary conditions. A mini Single Edge Notched Tensile sample manufactured by fused filament fabrication with ABS is studied. It is shown that both methods locally extract $J$-integrals, and the crack tip is accurately located by the FE-based method. By comparing computed displacements to those measured via DIC, it is possible to locally check the validity of the numerical model. The initiation and propagation stages are analyzed independently thanks to two different magnifications of acquired image series.
\end{abstract}

Keywords: Additive manufacturing; digital image correlation; finite element method; $J$ integral, crack propagation 


\section{INTRODUCTION}

The increased use of Additive Manufacturing (AM) in the production of functional and finished parts raises the level of quality requirements ${ }^{1}$. Therefore, the major challenge of AM research is to improve the mechanical properties using various experimental and numerical design techniques ${ }^{2}$. The most commonly used technology for making AM parts made of polymers is fused filament fabrication $(\mathrm{FFF})^{3,4}$. The process is based on the extrusion of a thermoplastic polymer filament through a heated nozzle deposited layer-by-layer to create parts from a digital model. Acrylonitrile-Butadiene-Styrene (ABS) is the most widely used and commonly studied polymer for $\mathrm{FFF}^{5}$.

Many studies focused on the tensile properties, although flexural ${ }^{6}$, torsional $^{7}$, and compressive $^{8}$ tests of FFF structures were reported as well. These studies showed that the mechanical properties depended on the material, in addition to the geometry and processing parameters (e.g., orientation, raster angle, raster width, filament size, gap, and temperature) ${ }^{9-}$ 16. There are few analyses on the fracture properties of AM polymer parts. Recently, there was a growing interest in the understanding of fracture for 3D printed polymers. Hart et al. ${ }^{17}$ explored the effect of layer orientation on the fracture properties of ABS obtained via FFF. The authors demonstrated that the inter-laminar fracture toughness (i.e., fracture between layers) was approximately one order of magnitude lower than the cross-laminar toughness (i.e., fracture through layers). Aliheidari et al. ${ }^{18,19}$ studied the fracture resistance and the interlayer adhesion of FDM 3D printed materials. It was shown that the fracture resistance was significantly affected by the nozzle temperature. Higher temperatures allowed for a good interlayer adhesion, which was found to be close to the fracture resistance of bulk $\mathrm{ABS}$. McLouth et al. ${ }^{20}$ analyzed how the fracture toughness varied with the underlying mesostructure. It was concluded that the orientation of individual tracks of deposited material with respect to the crack tip had the most pronounced role in altering the fracture toughness of $3 \mathrm{D}$ printed $\mathrm{ABS}$; an outcome previously proven by Brugo et $\mathrm{al}^{21}$ on laser sintered polyamide. Li et al. $^{22}$ confirmed that the fracture properties strongly depended on the build/raster orientations.

Although previous works have studied the effect of printing parameters on the fracture properties, most of them have focused on global scale analyses. Local measurements have not been incorporated to study in detail crack initiation and growth. Thus, knowing the important effect of mesostructures on the fracture of AM parts, the present work focuses on local measurements (i.e., at the microscale) via Digital image correlation (DIC). The kinematic 
measurements were further processed to extract fracture mechanics parameters. DIC is widely used to measure displacement fields, thanks to its ease of use for a wide range of materials including AM polymeric materials. Based on the kinematic field around a crack, CherepanovRice's $J$-integral ${ }^{23}$ was assessed to directly calculate the energy release rate from strain fields around a crack. Catalanotti et al. ${ }^{24}$ developed a method based on measured displacement and strain fields to extract crack resistance curves of cross-ply CFRP composite laminates. Later, Becker et al. ${ }^{25}$ evaluated the $J$-integral from the measured crack displacement field, which they coined JMAN. Excellent agreement with other fracture characterization techniques was reported when testing JMAN on elastic, elastoplastic and quasi-brittle materials ${ }^{25,26}$.

In order to evaluate the $J$-integral for a power-law hardening material, Yoneyama et al. ${ }^{27}$ used three methods, that is, the path integral method, the domain integral method and least squares fit with the Hutchinson, Rice and Rosengren (HRR) field ${ }^{23,28}$. The $J$-integral was estimated from strains and stresses computed from DIC measured displacements. It was shown that the $J$-integral could be estimated accurately by such methods ${ }^{27,29}$. Other hybrid methods have also been developed ${ }^{30-33}$. Barhli et al. ${ }^{33}$ proposed an approach transferring displacements experimentally measured via DIC to perform finite element simulations to extract the $J$-integral with the commercial code ABAQUS. The advantages underlined in the afore-cited works over other methods are geometric freedom, namely, the method can be applied to any type of tested sample $^{24,27,33}$. It is also insensitive to inelastic strains close to the crack tip ${ }^{25,26} . J$-integral evaluations using directly measured crack displacement fields and/or hybrid methods are likely to be transferable to AM polymeric materials. Very recently, Issac et al. ${ }^{34}$ applied the approach of Barhli et al ${ }^{33}$ to examine the fracture behavior of three in-plane FFF printed architectures made of ABS.

In the present work, a combined computational and experimental investigation is performed to study the fracture behavior of 3D printed ABS specimens. A local analysis is performed to evaluate fracture mechanics parameter (i.e., $J$-integral) via displacement and strain fields using DIC, and coupling them with finite element simulations. The so-called mini single edge notch tension (mini-SENT) specimen is first introduced. The microscale experiment analyzed via DIC enables surface displacement and strain fields to be measured ${ }^{35,36}$. To study the effect of the underlying mesostructure on the fracture properties of additively manufactured materials, numerical tools are developed herein to make the best use of microscale experimental results. Based on kinematic fields, the crack tip location and $J$-integral are assessed by two independent methods. On the one hand, FE calculations are run with ABAQUS ${ }^{37}$ using measured 
displacements as boundary conditions. The crack tip position is found by minimizing the error between computed and measured displacement fields. The $J$-integral is assessed with the builtin interaction integral ${ }^{38,39}$. On the other hand, MATLAB scripts are developed to find the crack tip position and calculate the $J$-integral using the measured kinematic fields.

\section{EXPERIMENTAL SET-UP AND PROTOCOL}

\subsection{Specimen preparation}

A mini-SENT specimen was 3D printed (dimensions shown in Figure 1(A)) by adding fused filaments of Acrylonitrile Butadiene Styrene (ABS) using a Makerbot replicator 2X 3D printer. The extrusion temperature was set to $230^{\circ} \mathrm{C}$, and the fabricated plate was heated up to $110^{\circ} \mathrm{C}$. The sample was printed as a solid part, in a flat part orientation and $\left[+/-45^{\circ}\right]$ configuration (Figure 1(B)). The part was made of 24 layers whose individual thickness was $0.25 \mathrm{~mm}$. The notch dimensions meet ASTM E1820 $0^{40}$ and ASTM D6068 ${ }^{41}$ standard recommendations, namely, specimen width and initial crack length. The notch was also printed and formed by two contour layers that were locally welded together under the effect of deposition temperature. As will be shown herefater, this welded joint will suddenly break during the test. Thus, the crack first had to propagate and break these contours before reaching the $+/-45^{\circ}$ printed layers.

In order to make surface functionalization easier, the specimen was mechanically polished. The thickness of the specimen was reduced from $6 \mathrm{~mm}$ to $3 \mathrm{~mm}$. The surface after polishing is shown in Figure 1(C). At this scale, porosities generated at the interfaces between filaments are visible in addition to the printing sequence made of $+/-45^{\circ}$ layers. White speckles with micrometric dimensions were deposited using an airbrush (speckle diameter varying between $10 \mu \mathrm{m}$ and $30 \mu \mathrm{m}$ with an average of $20 \mu \mathrm{m}$, see Figure $\mathbf{1}(\mathbf{D}))^{35}$. 


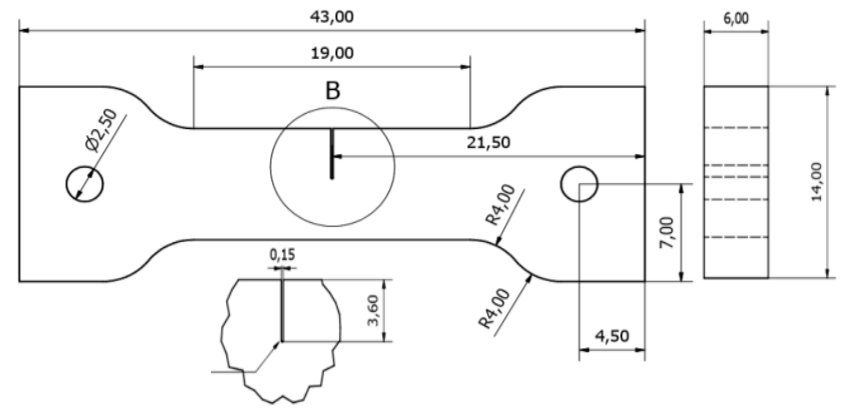

(A)

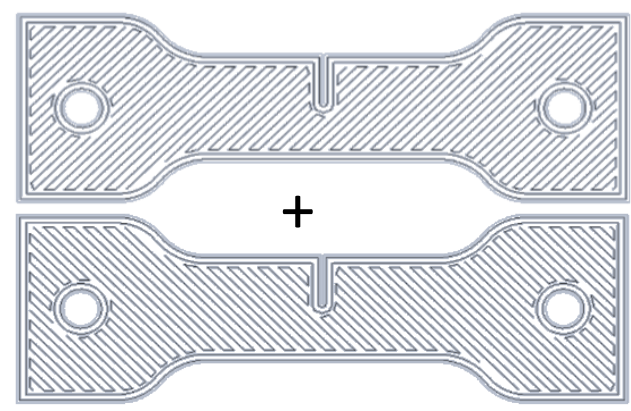

(B)

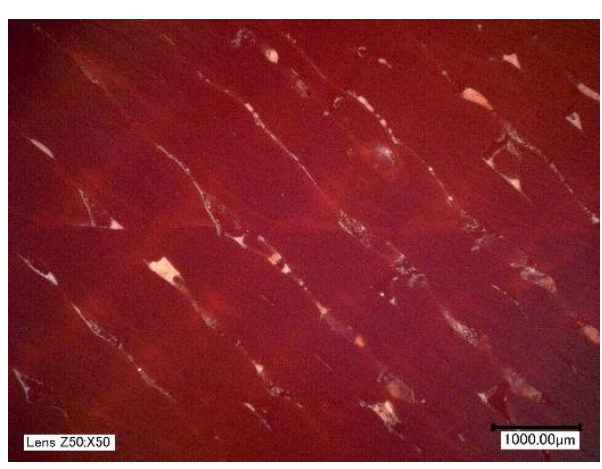

(C)

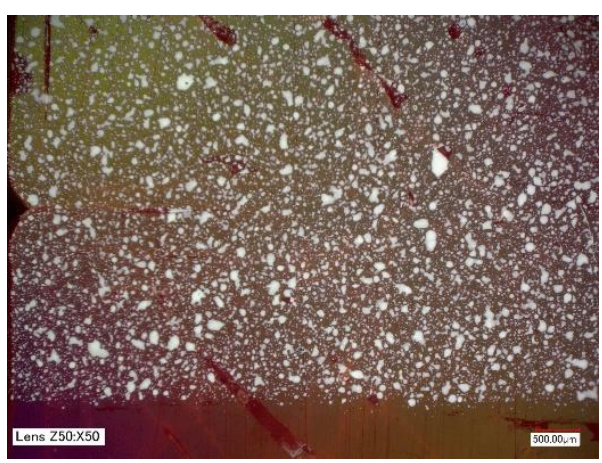

(D)

Figure 1: (A) Sample dimensions (in $\mathrm{mm}$ ). (B) Printing sequence for $+/-45^{\circ}$ layers.

(C) Raw and (D) speckled surface

\subsection{In situ tensile test}

The experimental setup consisted of a numerical Keyence VHX-1000 microscope for surface observation, a tensile mini machine and a triggering system (Figure 2). The latter allowed images to be recorded at specific rates when the specimen was continuously loaded and each image to be related to the corresponding applied load. Since the notch was welded due to the temperature of filament deposition and the dimension of the notch (i.e., $150 \mu \mathrm{m}$ in width), the magnification power was set to the lower lens range value $(100 \times)$ in order to monitor a wide enough region to monitor notch opening. When its opening was detected, a $(2 \times)$ zoom was applied in the vicinity of the notch root with no interruption of the test.

During the test, one frame per second was acquired until specimen failure and stored directly in tagged image file format (tiff) from the Keyence processing software. The acquired image quality was satisfactory (i.e., sufficient contrast and pattern feature size, Figures 1(D) and 2) and no additional treatments were required before DIC analysis. This qualitative statement was further confirmed after the uncertainty quantification reported in the sequel. The depth of field of the selected magnifications was sufficient because it was not necessary to change the microscope calibration during the test. This observation proves that the out-of-plane displacements remained very small to induce artifacts for 2D-DIC. 


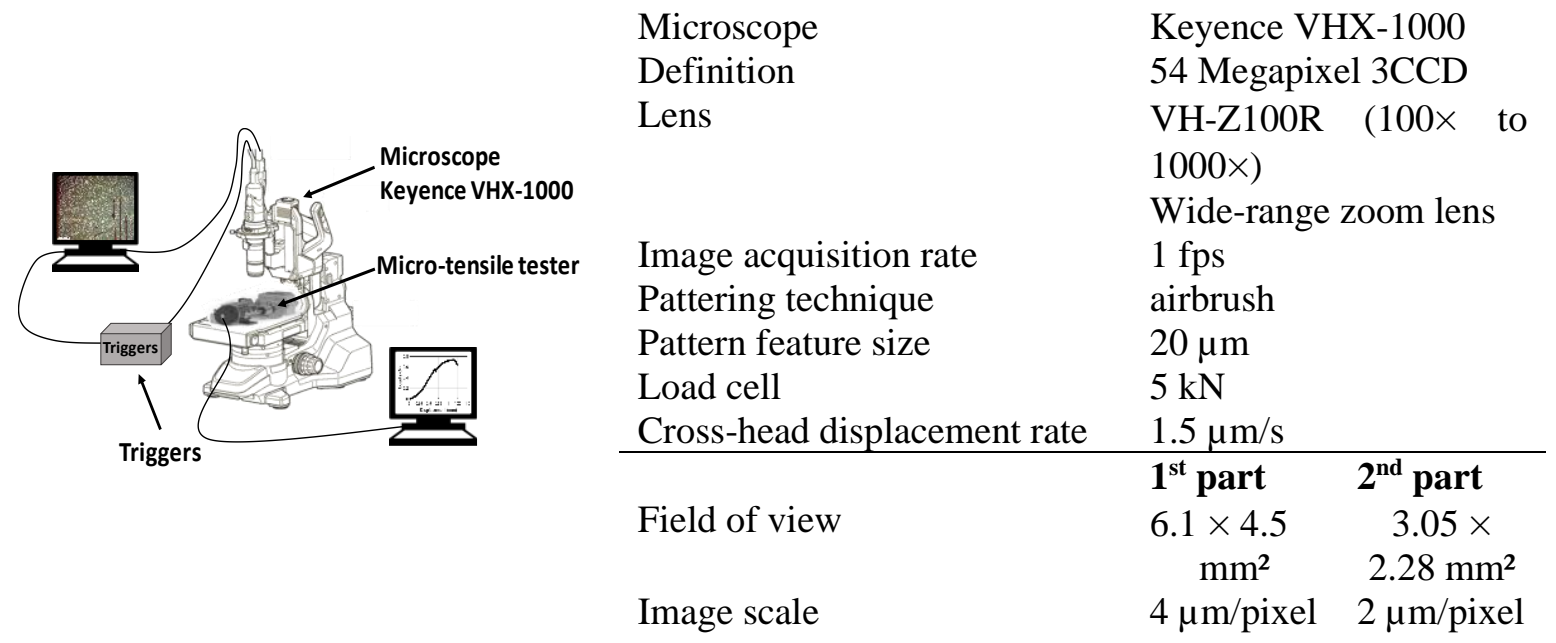

Figure 2: Experimental setup and hardware information

\subsection{Kinematic field measurement}

DIC provides displacement fields ${ }^{42}$. From an image of the surface in reference and deformed states, 2D displacement vectors were retrieved by registering 25-px in radius subsets. DIC resolutions are now sufficient to analyze experiments performed at various scales ${ }^{43,44}$. In the present study, $\mathrm{Ncorr}^{45}$ was used to register the microscopic images acquired during the test $\mathrm{t}^{36}$. The matching criteria used in the DIC code were the normalized cross-correlation, and then the normalized sum of squared differences. The subset spacing was set to 3 pixels. Strains were calculated with the 2D Savitzky-Golay (SG) digital differentiator ${ }^{45,46}$. The strain window size consisted of $5 \times 5$ measurement points. To evaluate the measurement uncertainties, a DIC analysis was conducted on 20 images prior to the test itself. The standard displacement uncertainty was equal to $0.1 \mu \mathrm{m}$, and the standard strain uncertainty to $1.2 \times 10^{-4}$.

Figure 3 shows the load vs. strain curve, where $\varepsilon_{y y}$ is the average strain in the tensile direction. This curve is associated with longitudinal (Euler-Almansi) strain maps in order to illustrate the main local features on the specimen surface. Two zones are observed. The first zone corresponds to elastic deformations of the material. This elastic response was stopped at step 562 by the load drop, which is due to notch reopening. The notch of the designed specimen was not correctly printed, and the filaments of the outline, which should make up the notch were welded. Consequently, the strain was uniformly distributed on the material surface. At step 551, strain concentrations were observed around the notch, just before reaching step 562 where weld line failure occurred. The notch fully opened along its length, which was equal to $3.6 \mathrm{~mm}$. At this step, a zoom was operated to focus on the notch root. The field of view was 
then changed from $6.1 \times 4.5 \mathrm{~mm}^{2}$ to $3.05 \times 2.28 \mathrm{~mm}^{2}$ (this is called part 2 of the test). In that part, the highest strain concentration was found at the notch root. Elsewhere, strain distributions were more uniform until step 648 where non-uniform distributions appeared. The strain levels in these zones are higher than the yield strain of this material, which is estimated (for $+/-45^{\circ}$ confiugrations) to be about $0.02^{34,47}$. The shape of the concentration zones is due to the filaments deposition orientations (Figure 1(D)). They appear at right angles caused by the intersection of $+45^{\circ}$ and $-45^{\circ}$ orientations. The strain is no longer concentrated in the crack vicinity but also in the joints between filaments. The deformation at these zones increased, thereby creating multiple cracks in welding lines that ultimately induced global failure. The load drop was progressive because of one-by-one filament failure.

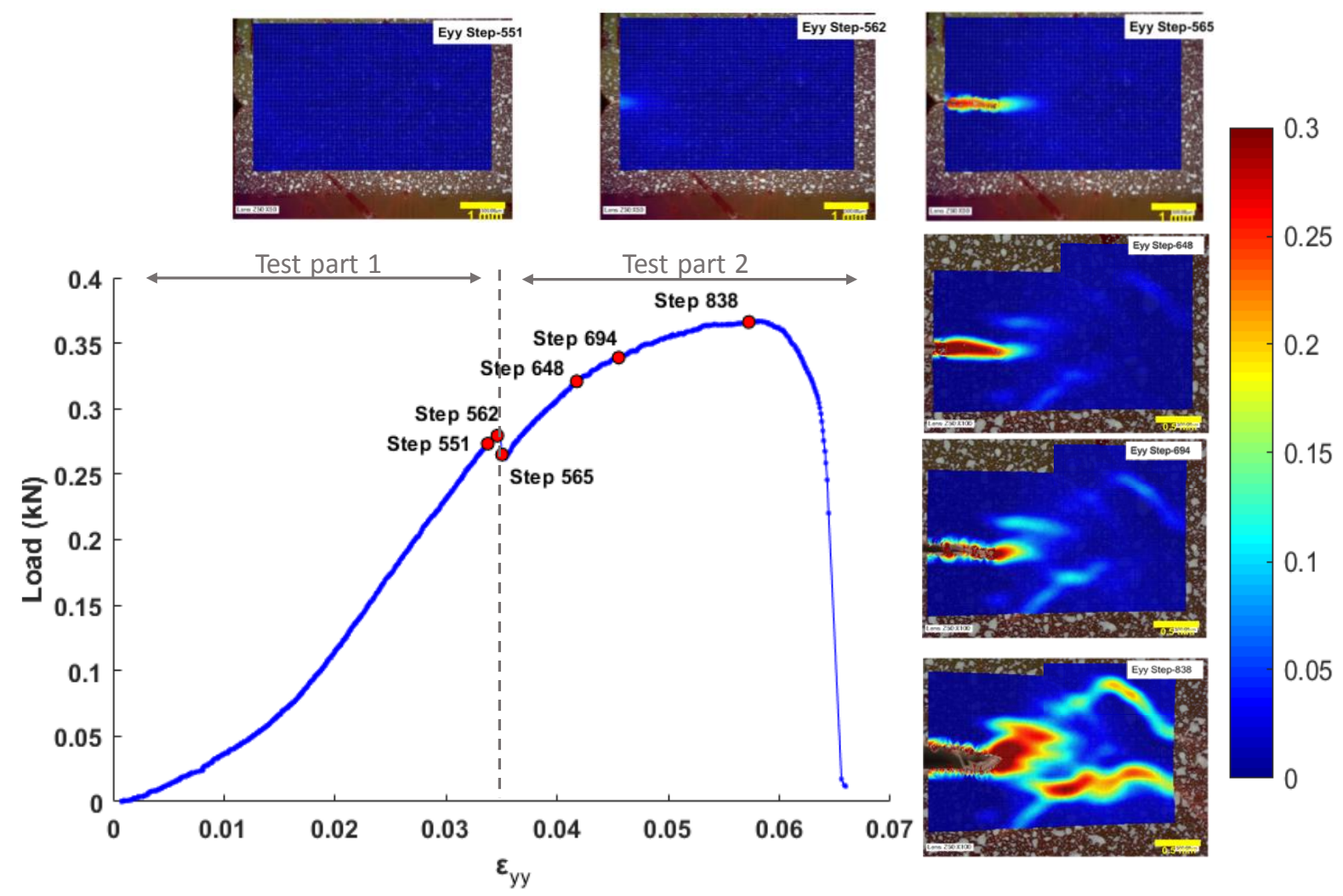

Figure 3: Strain field analysis of fracture events and corresponding load vs. mean longitudinal strain curve

\section{CRACK TIP LOCATION}

The first question to address when analyzing the fracture behavior is the location of the crack tip. This is an experimental challenge ${ }^{48}$. The most widely used technique for crack propagation monitoring is to resort to direct observations by optical means ${ }^{49}$. The resolution in 
terms of crack opening is of the order of one pixel, which can be satisfactory if an optical microscope is used. Crack growth measurement can thus be carried out with a micrometric resolution. This approach, despite its simplicity, usually is very delicate and extremely slow. On certain types of material, the visual identification of the crack tip is not obvious, which makes it imprecise. In the present case, because the surface was speckled for DIC purposes (Figure 1(D)) such approach was not possible. Image processing by DIC allows for crack growth measurement from subsequent analyses, or as a direct output of the correlation procedure. So-called "integrated approaches" (or I-DIC ${ }^{50-52}$ ) were followed to directly determine the crack tip location. Most of the approaches to measure crack growth using DIC were based on post-processing the measured displacement fields ${ }^{24,32,53,54}$. This approach is also used herein to locate the crack tip.

Two procedures are presented and tested on the present experiment. The first one is based on strain field analysis ${ }^{36}$. The second one uses FE calculations to determine the crack tip location by minimizing the distance between measured and computed displacement fields $\mathrm{s}^{32,55}$. It belongs to the class of finite element model updating techniques ${ }^{56}$.

\subsection{Procedure 1 (analysis of Euler-Almansi strain maps)}

In the crack vicinity, the longitudinal strain reaches its maximum level very close to the crack tip. The crack tip position can be then found by locating the maximum strain. Hereafter, it was assumed that crack growth was obtained by tracking the motion of the point of maximum in the strain maps. The center of the subset where the strain was maximum was assumed to be the crack tip if the upstream region, which is in the wake of the fracture process zone, was free of discontinuities. The main procedure steps are shown in Figure 4. 


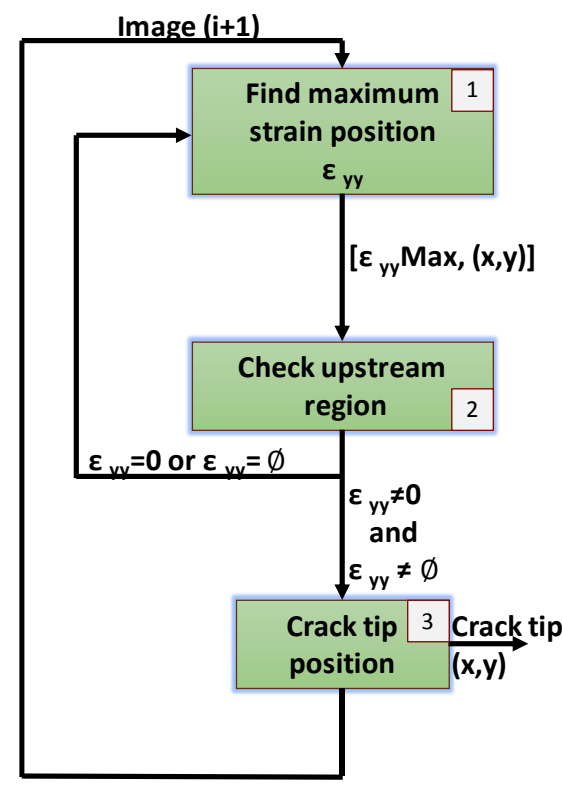

(A)

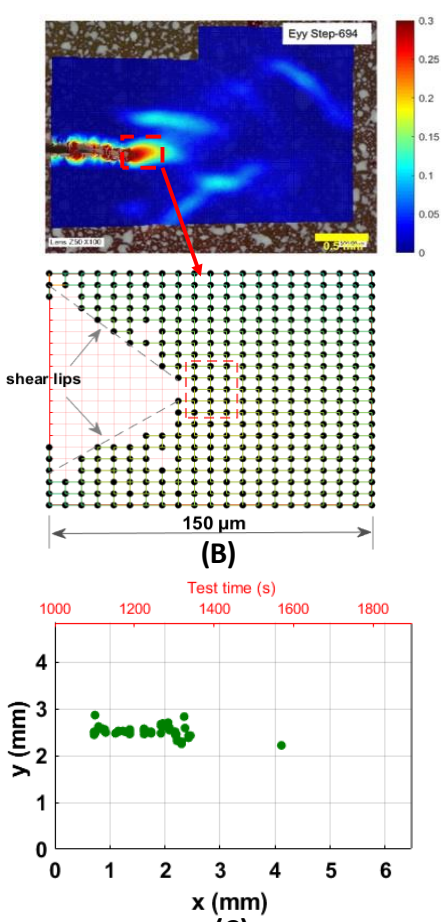

(C)

Figure 4: (A) Crack tip location algorithm. (B) Strain matrix representation. (C) Crack tip position ${ }^{36}$

\subsection{Procedure 2}

For this second procedure, a simple definition of the crack tip location was considered. It corresponded to the location for which the identification error between the measured ( $\left.\mathbf{u}_{\text {meas }}\right)$ and computed ( $\mathbf{u}_{\text {comp }}$ ) displacement fields was the smallest when the crack tip position $\mathbf{x}_{\mathrm{c}}$ is changed $^{32}$. FE calculations were conducted for every time step. Only the part inside the DIC region of interest was modeled. Boundary conditions were defined by prescribing the displacements of the external boundary of the ROI (see Figure 5). The computed displacements $\mathbf{u}_{\text {comp }}$ of all inner nodes are used to determine the crack tip position. The nodal displacement difference between DIC and FE analyses is computed, and the displacement gap consists in the root-mean-square difference

$$
\delta^{2}\left(\mathbf{x}_{c}\right)=\frac{1}{n_{m}} \sum_{m=1}^{n_{m}}\left\|\mathbf{u}_{\text {meas }}\left(\mathbf{x}_{m}\right)-\mathbf{u}_{\text {comp }}\left(\mathbf{x}_{m}, \mathbf{x}_{c}\right)\right\|^{2}
$$

where $\mathbf{x}_{c}$ is the (vector) position of the considered crack tip node, $n_{m}$ the number of measurements located at $\mathbf{x}_{m}$. 


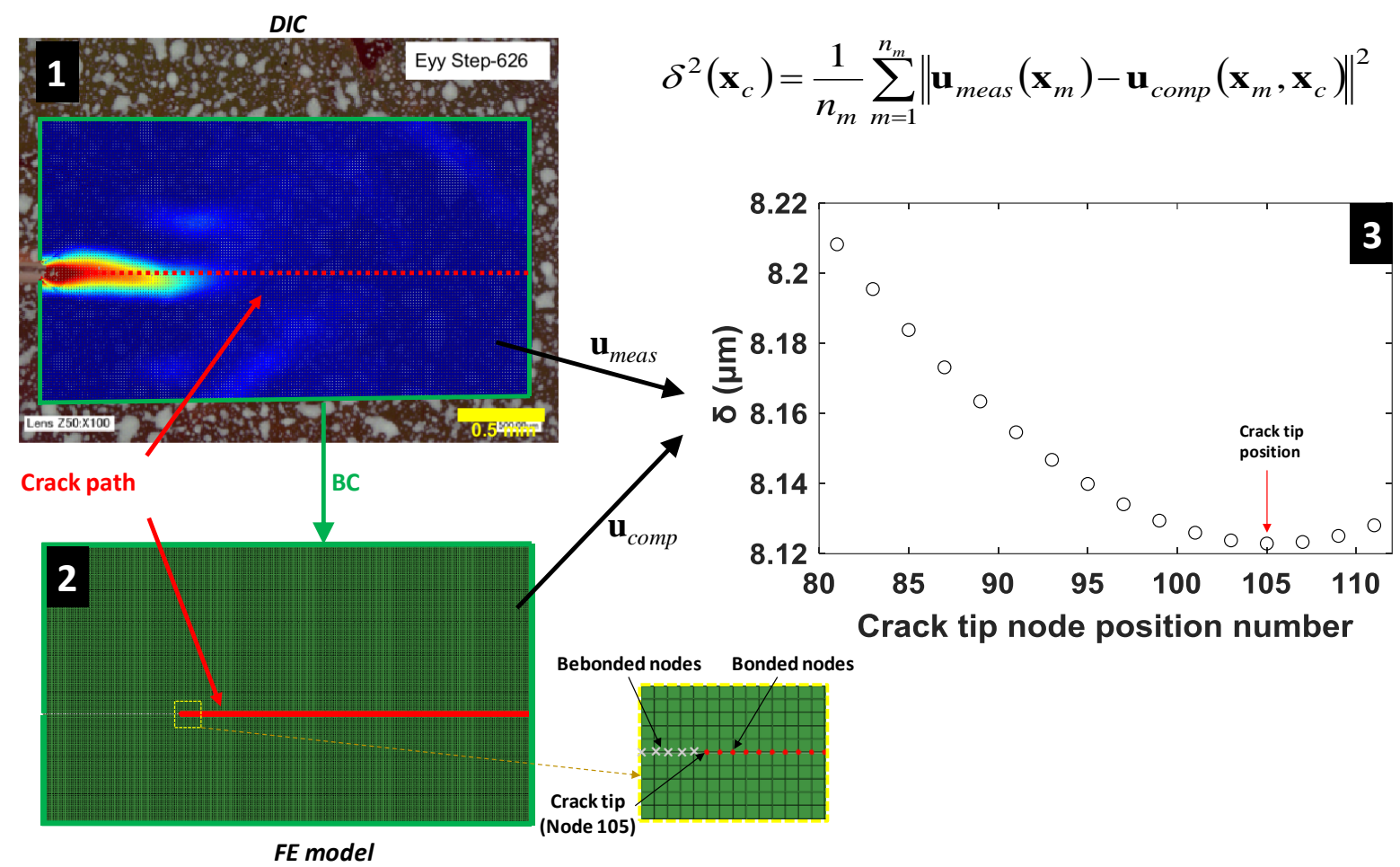

Figure 5: Measured boundary conditions prescribed to the FE model and schematic view of the crack tip location procedure

In the finite element model, the ROI was modeled as a 2D rectangular area meshed with four-node plane stress elements (CPS4). The mesh size is the distance between consecutive subset centers. In this way, the number of nodes in this model was identical to the number of DIC subsets (Figure 5). The behavior of the ABS material obtained by FDM was assumed to be elastic and orthotropic. The elastic properties of each layer are as follows: $E_{1}=1680 \mathrm{MPa}$, $G_{12}=545 \mathrm{MPa}, E_{2}=1415 \mathrm{MPa}, v_{12}=0.37$, where the longitudinal direction of the layer is 1 , the transverse direction is 2 . These values were determined by performing a series of tensile tests on $\left[0^{\circ}\right],\left[ \pm 45^{\circ}\right],\left[90^{\circ}\right]$ configurations ${ }^{47}$. The same $3 \mathrm{D}$ printer and ABS filament were used to manufacture those samples. The printing parameter set was identical as well ${ }^{36,57}$.

For each load step, several crack tip positions were considered along the crack path. For each chosen position, an FE calculation was performed to obtain the nodal displacements. Then, these displacements were compared to those measured by calculating the identification error (1). The FE result that was closest to reality yields the smallest error. Figure 6 shows the identification error as a function of virtual crack positions in two steps of test part 1 (Figure 6(A)) and test part 2 (Figure 6(B)). The parabolic shape of the curves highlights the presence of a global minimum, which is the best approximation of the position of the crack tip. 


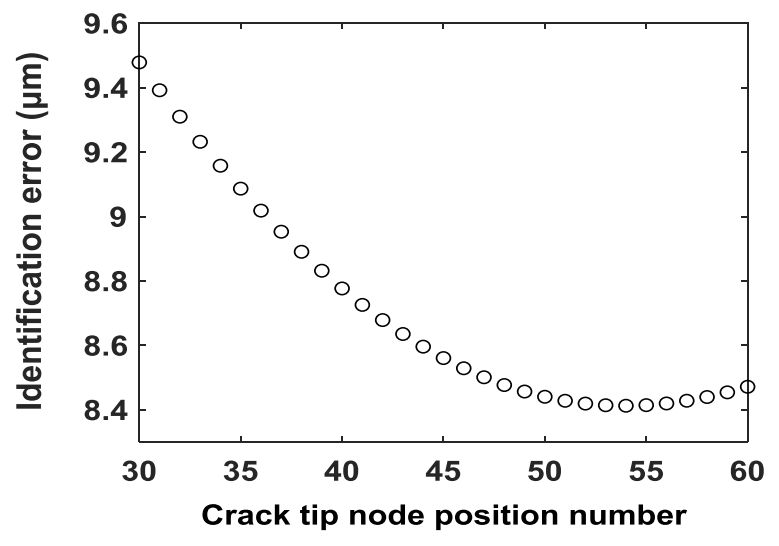

(A)

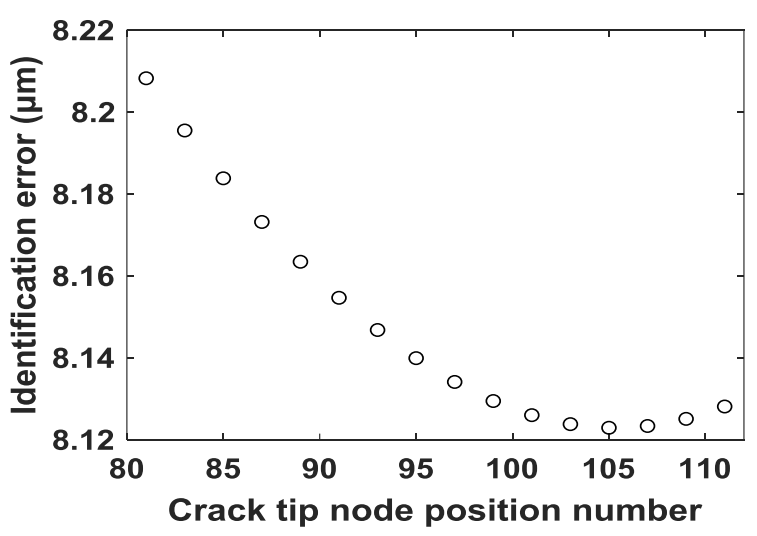

(B)

Figure 6: Identification error $\delta$ as a function of crack position for (A) step 563, and (B) step 626

Procedures 1 and 2 were fully automated within a Matlab environment. In procedure 2, for each step (or image), an initial crack tip position was considered on the defined crack path. The crack tip was set to be at the position found in the previous image (starting from node 3 for the first image). Then, 5 simulations were conducted considering the selected position, the next 3 downstream and the previous upstream positions. The identification error was calculated for each simulation. If the error-tip position curve was not strictly decreasing, the crack tip position was the one with the smallest identification error. Otherwise (i.e., the error-tip curve is strictly decreasing), 5 new simulations were run in which the selected position is that with the lowest error of the previous calculations. Generally, only 5 simulations were needed. Consequently, nonlinear least squares procedures were not followed ${ }^{27,51,53}$. For each simulation batch, the finite element calculations, the comparison between measured and calculated displacements and the error calculation lasted 5 minutes in all. Thus, for each image, procedure 2 took between 5 and 15 minutes (depending on the crack propagation increment) to locate the crack tip position. Compared to procedure 2 , procedure 1 was faster especially at the beginning of the test when the only strain concentration zone is near the crack tip but when heterogeneities in the strain maps appears, the identification procedure becomes slower (for example, the application of procedure 1 on this test took $3 \mathrm{~h}$ ). 


\subsection{Results and discussion}

\subsubsection{Identification error analysis}

Beyond the location of the crack tip, procedure 2 makes it possible to identify the domains of validity of the assumptions made in the FE model. For each load step, the identification error was calculated using equation (1), and its minimum value is reported in Figure 7. Two regimes were observed when analyzing the identification error as a function of the loading steps (Figure 7). First, when there was no crack on the surface of the material, the identification error did not exceed $2 \mu \mathrm{m}$ (Figure 7(A), until step 562). When compared to the noise floor uncertainty (i.e., $0.1 \mu \mathrm{m}$ ), it is concluded that a macroscopic elastic model was a good first order approximation of the sample behavior. Second, when reaching step 562, the crack initiated and propagated causing notch filament weld line failure (see Subsection 2.3). There was a sudden increase of the identification error (from $2 \mu \mathrm{m}$ to $8.2 \mu \mathrm{m}$ ). This increase was due to the development of the fracture process zone that gave rise to nonlinearities confined in its vicinity. The perfectly elastic behavior assumed in the finite element model did not take into such phenomena so the computed strains in this area were underestimated.

The propagation phase was analyzed in the second part of the test (Figure 7(B)). From step 566 on, a zoom was operated on the notch bottom vicinity. Thus image 566 is the new reference image for DIC, which resets the measured displacements. This reset explains the fact that the identification error again starts from very low values. The error increased in two stages. The first one, up to image 710, was a gradual growth because the largest part of the difference between the measured and computed displacements essentially came from the fracture process zone where increasingly pronounced plasticity took place. Beyond step 710, several areas of plastic deformation and damage appeared elsewhere than round the crack tip so that the error increased more rapidly. Heterogeneities in the strain maps (Figure 3) were due to the mesostructure of the material obtained by $\mathrm{AM}^{36}$. 


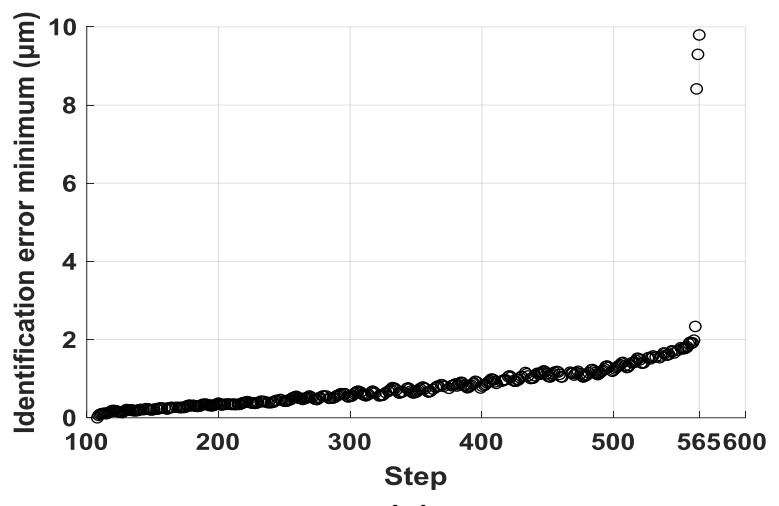

(A)

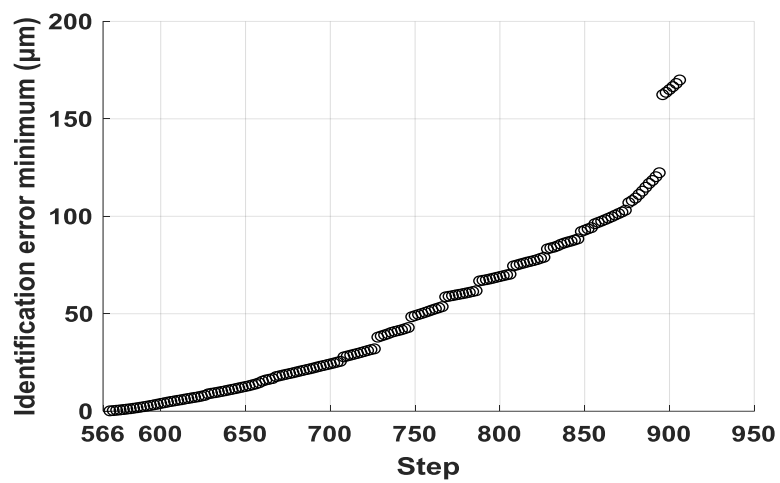

(B)

Figure 7: Identification error $\delta$ for $(A)$ test part 1 , and (B) test part2

\subsubsection{Crack growth}

Figure 8 shows the crack extension history obtained by applying both procedures. At the beginning of the test, no crack propagation was noticeable. Both methodologies had high uncertainties for the first steps due to the very small displacement ranges. Once reaching step 562 , the crack initiated and propagated between the two filaments forming the edge of the notch. In the second part of the test (from step 565 on), the displacement fields were reset because of the magnification change. Despite small displacement levels, it was observed that the FE procedure identified smaller crack lengths than the strain field-based procedure. The presence of the crack did not necessarily cause discontinuities in the measured strain fields. For this reason, the first procedure did not detect crack growth on the first 70 images. It is therefore believed that the results provided by procedure 2 are more trustworthy in this first part of propagation. From step 636 on, when the deformation becomes sufficiently large compared to the reference state (step 566) the propagation of the crack was detected. Beyond step 690, both procedures converged to similar values of $\Delta a$ with a maximum offset of $6 \%$. This analysis highlights the precision of the method based on FE analyses (procedure 2). Its ability to detect crack growth even in the case of small deformations is a strong advantage. This capability was useful in this study to be able to continue following the crack propagation even with a change in microscope magnification and with the re-initialized kinematic fields. 


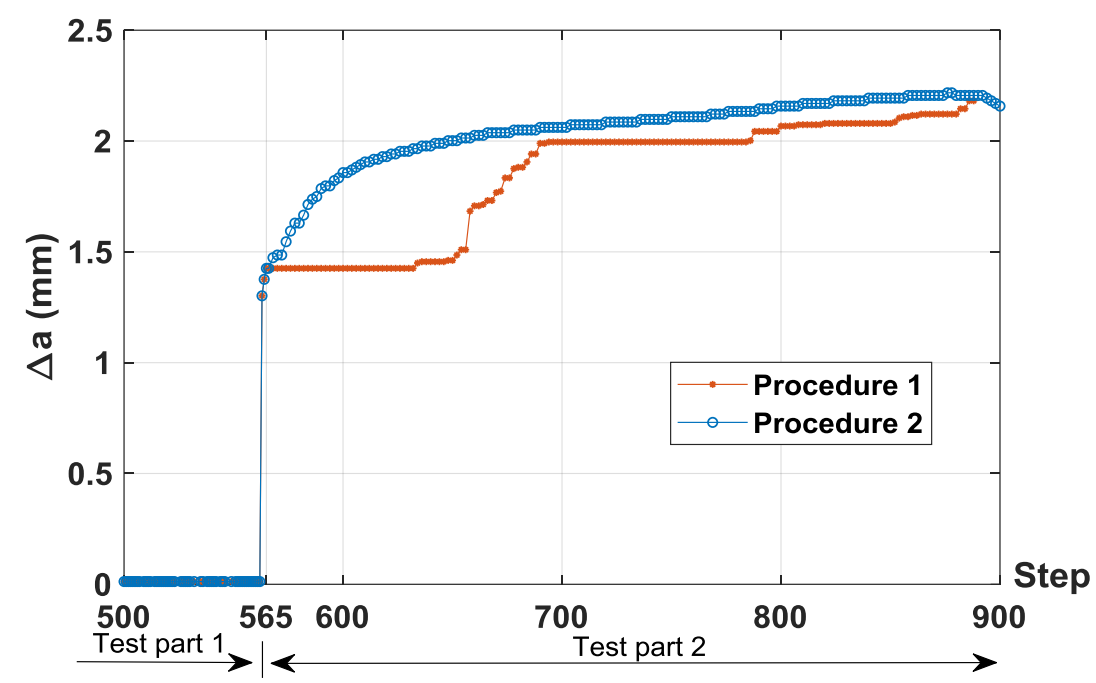

Figure 8: Crack growth history determined by both procedures

Last, let us note that in procedure 1 , the complexity of the crack path can be taken into account since the crack tip search is performed on a domain located downstream of the crack. For the second procedure, the tip of the crack is located along a pre-determined path, which was straight in the present case (Figure 5). Otherwise, thanks to correlation analyses (with the use of gray level residuals ${ }^{58,59}$ ) the crack path can be tailored to its actual topography. The displacement residuals can also be checked to validate a posteriori the a priori choices.

\section{J-INTEGRAL CALCULATION}

To evaluate the $J$-integral, experimentally measured displacement and strain fields via DIC were used. Then, the stresses were evaluated locally by assuming orthotropic elasticity to apply along the considered contour. Another route was provided by the FE code with its built-in (domain) procedure. In that case, measured Dirichlet boundary conditions were applied to the elastic model. It is worth noting that the $J$-integral evaluations reported hereafter used contours or domains centered on the estimated crack tip positions by both procedures.

\subsection{Methodology}

To calculate the $J$-integral from measured displacement and strain fields, the stresses need to be evaluated. The parts fabricated by FDM were made layer by layer, which led to a mechanical behavior similar to that of laminated structures ${ }^{60-62}$. A plane stress assumption was made for each layer. In that case, the strain-stress relationship is written as 


$$
\left\{\begin{array}{l}
\sigma_{x x} \\
\sigma_{y y} \\
\tau_{x y}
\end{array}\right\}=\left[\begin{array}{ccc}
\bar{Q}_{11} & \bar{Q}_{12} & 0 \\
\bar{Q}_{12} & \bar{Q}_{22} & 0 \\
0 & 0 & \bar{Q}_{66}
\end{array}\right]\left\{\begin{array}{l}
\varepsilon_{x x} \\
\varepsilon_{y y} \\
\gamma_{x y}
\end{array}\right\}
$$

where $(x, y, z)$ is the global coordinate system, $(1,2,3)$ the local coordinate system, $\bar{Q}_{i j}$ the components of the stiffness matrix calculated by using the transformation matrix, $[\mathbf{T}]$, between the two coordinate systems

$$
[\mathbf{T}]=\left[\begin{array}{ccc}
\cos ^{2} \theta & \sin ^{2} \theta & 2 \cos \theta \times \sin \theta \\
\sin ^{2} \theta & \cos ^{2} \theta & -2 \cos \theta \times \sin \theta \\
-\cos \theta \times \sin \theta & \cos \theta \times \sin \theta & \cos ^{2} \theta-\sin ^{2} \theta
\end{array}\right]
$$

Then, $[\overline{\mathbf{Q}}]$ is written as

$$
[\overline{\mathbf{Q}}]=[\mathbf{T}]^{-1}\left[\mathbf{Q} \llbracket[\mathbf{T}]^{-T}\right.
$$

The $J$-integral is a measure of the energy release rate in a cracked medium and is expressed, in the form of a contour integral ${ }^{23}$

$$
J=\oint_{\Gamma}\left(w d y-\mathbf{t} \frac{\partial \mathbf{u}}{\partial x} d s\right)
$$

where $\Gamma$ is a contour surrounding the notch tip, $w$ the strain-energy density, $\mathbf{t}$ the traction defined with the outward normal along $\Gamma$, u the displacement vector, and $s$ the curvilinear abscissa along $\Gamma$.

Several methods were proposed to calculate experimentally the $J$-integral ${ }^{24,25,27}$. Thanks to the similarity between additively manufactured materials and composites, the formulation such as that proposed by Catalanotti et al. ${ }^{24}$ may prove suitable for 3D printed materials. To calculate the $J$-integral in a composite material, the authors proposed a formulation derived from Rice's work $^{23}$. It is calculated using displacement, strain and stress data with a rectangular contour enclosing the crack tip. The $J$-integral was computed point-by-point along each edge of the contour $^{24}$

$$
J=\int_{\Gamma}\left(\frac { 1 } { 2 } \left\{-\bar{\sigma}\left\{\{\boldsymbol{\varepsilon}\}^{T} n_{1}-\left\{\frac{\partial \mathbf{u}}{\partial x_{1}}\right\}^{T}[\overline{\boldsymbol{\sigma}}]\{\mathbf{n}\}\right) d s\right.\right.
$$

where $\{\boldsymbol{\sigma}\}$ is the average stress vector, $\{\boldsymbol{\varepsilon}\}$ the corresponding strains, $\{\mathbf{n}\}$ the contour normal, $n_{1}$ the contour normal in the crack direction, and $\left\{\partial \mathbf{u} / \partial x_{1}\right\}$ the displacement gradient. The mini- 
SENT sample was made by a succession of $+45^{\circ}$ and $-45^{\circ}$ layers. The average stresses were computed from the transformed stiffness matrices of the $+45^{\circ}$ and $-45^{\circ}$ plies, $\left[\overline{\mathbf{Q}}^{+45}\right]$ and $\left[\overline{\mathbf{Q}}^{-45}\right]$ respectively, as $\{\overline{\boldsymbol{\sigma}}\}=\frac{1}{2}\left(\left[\overline{\mathbf{Q}}^{+45}\right]+\left[\overline{\mathbf{Q}}^{-45}\right]\right)\{\boldsymbol{\varepsilon}\}$. The derivative of the displacement fields was calculated as

$$
\left\{\frac{\partial \mathbf{u}}{\partial x_{1}}\right\} \approx\left\{\frac{\Delta \mathbf{u}}{\Delta x_{1}}\right\}=\left\{\frac{\mathbf{u}^{i+1}-\mathbf{u}^{i-1}}{2 \Delta x_{1}}\right\}
$$

The $J$-integral was then assessed from the sum of all discrete contributions of each subset center.

In the present case, contour integrals were used to evaluate $J$. An alternative route is to resort to domain integrals ${ }^{63-65}$. This path was not followed in this first procedure because nonlinearities were suspected to occur in the vicinity of the crack tip. Conversely, procedure 2 utilized built-in methods of the selected FE code.

\subsection{Method validation}

Since the $J$-integral is path independent ${ }^{23}$, different contours were considered. However, to avoid nonlinear effects in the vicinity of the crack tip, the path independence was carefully checked on domains not too close to the crack tip ${ }^{27,34}$. Further, the method was also applied to displacement and strain fields obtained by a finite element calculations. Then the $J$-integral was computed based on kinematic fields obtained by DIC measured on the surface of the specimen.

\subsubsection{Application with FE kinematic fields}

DIC measured displacements were taken as boundary conditions and the FE code computed displacements and strains over the considered surface (Figure 5). Based on these computed fields, the $J$-integral was calculated using both methods described above. Twenty-five contours were chosen in the crack tip vicinity area. The first contour (contour 45) was positioned at a distance of $270 \mu \mathrm{m}$ from the crack tip and the last one (contour 70) at $420 \mu \mathrm{m}$. This area was chosen far enough from the crack tip to avoid possible experimental nonlinearities. The strategy for constructing and designating these contours is described in Figure 9(A). Contour $N$ is a square centered about the crack tip and passing through the $N^{\text {th }}$ crack path node to the right. The $J$-integral levels calculated on these contours are compared in Figure $\mathbf{9}(\mathbf{B})$ to those determined directly by the FE code [31]. Both methods give constant values for all selected 
contours. Last, there was a systematic offset of $4 \%$ between the two methods. This was level was considered sufficiently small to validate the present implementation.

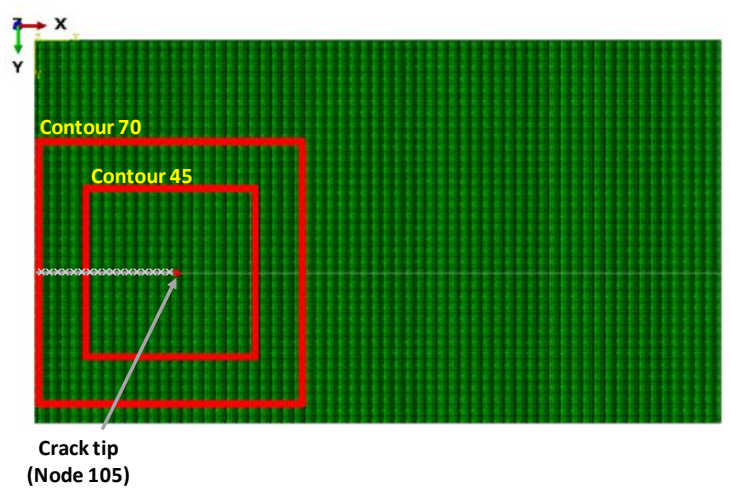

(A)

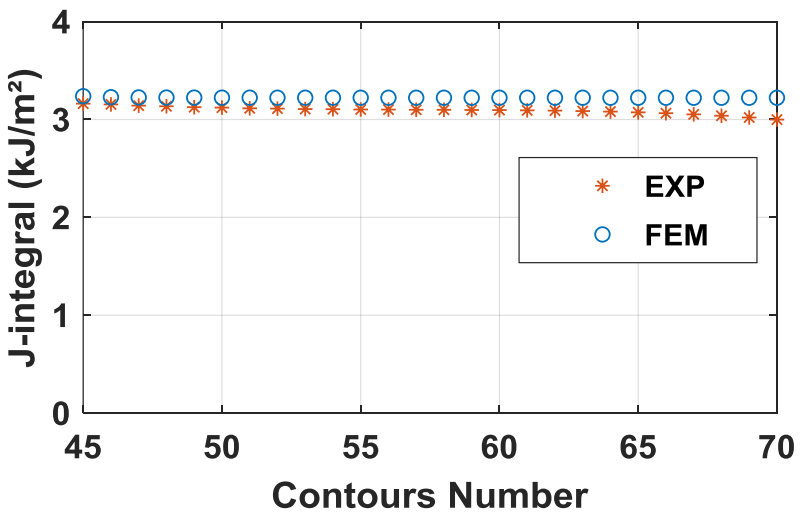

(B)

Figure 9: (A) Contours selected to calculate the J-integral. (B) J-integral as a function of contour number (step 666) for both procedures.

\subsubsection{Application to experimental fields}

Kinematic fields measured by DIC on the surface of additively manufactured ABS sample were used to calculate the $J$-integral. The average stresses were computed from the transformed stiffness matrices (expressed in $\mathrm{MPa}$ ) of the $+45^{\circ}$ and $-45^{\circ}$ plies

$$
\left[\overline{\mathbf{Q}}^{-45}\right]=\left[\begin{array}{ccc}
1700 & 687 & -76 \\
687 & 1835 & -58 \\
-76 & -58 & 527
\end{array}\right] \text { and }\left[\overline{\mathbf{Q}}^{+45}\right]=\left[\begin{array}{ccc}
1700 & 687 & 76 \\
687 & 1835 & 58 \\
76 & 58 & 527
\end{array}\right]
$$

leading to the global stiffness matrix

$$
[Q]=\left[\begin{array}{ccc}
1900 & 705 & 0 \\
705 & 1600 & 0 \\
0 & 0 & 545
\end{array}\right]
$$

It is worth noting that the elastic properties are nearly isotropic, which is to be expected for FFF-made samples.

Figure 10 shows the effect of the contour position on the $J$-integral computed at step 666. The levels of the $J$-integral of the closest contours to the singularity were not taken into consideration $^{27}$. Large deformations in that area may bias the results ${ }^{66,67}$. For contours located farther away from the crack tip, the results were close with a gap not exceeding $1.7 \%$. The contour independence confirms that the computation of the $J$-integral in an AM polymeric 
material can be made by following the method based on DIC measured fields. This method was presented in the literature as being independent of the crack tip location, by considering a contour large enough to contain the crack tip throughout the test ${ }^{25,26}$.

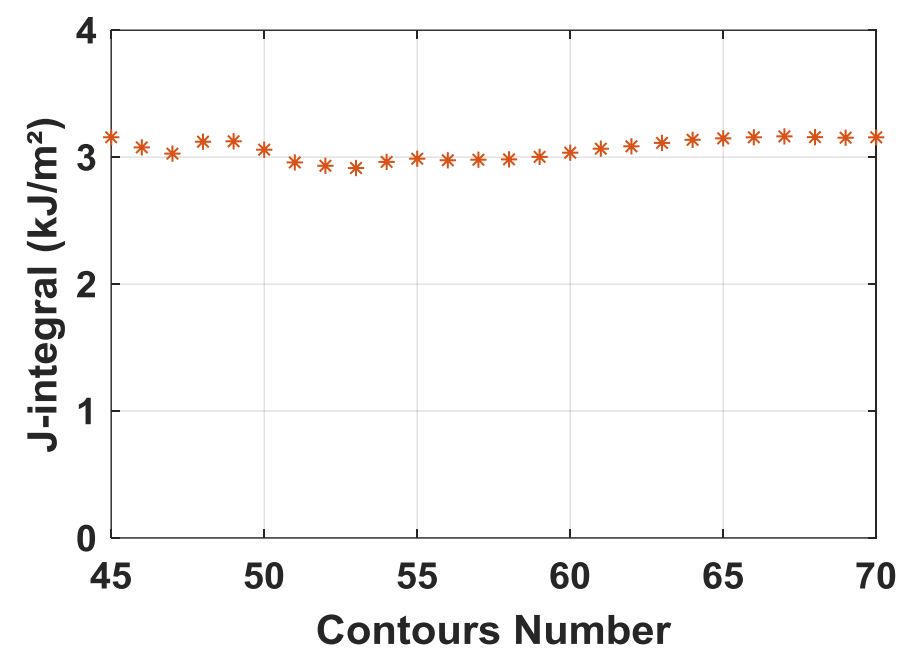

Figure 10: J-integral as function of contours number (step 666)

Such approach makes it possible to obtain the change of $J$ without necessarily locating the point of the crack tip, a task that may be complicated to carry out. Thanks to the two procedures of crack tip location presented in Section 2, the effect of crack tip location on the level of $J$ can be analyzed. This task will be the subject of the next section.

\subsection{Results and discussions}

\subsubsection{Crack tip location effect}

The $J$-integral was computed by contour integration using experimentally measured strains and displacements. Both crack extension laws (Figure 8) were considered. For each load step, the contour was placed in such a way that it contained the crack tip while ensuring that most of the surface it covered was in front of the crack tip.

Figure 11 shows the $J$-integral history in both parts of the test. At the beginning of the test (Figure 11(a)), the $J$-integral was null because no crack was detected on the surface of the material until step 540. From this step on, strain concentrations occurred at the location where the crack initiated. This phase, which preceded the actual initiation (between steps 540 and 562 ), gave rise to nonzero values of $J$ that remained very low (i.e., less than $0.2 \mathrm{~kJ} / \mathrm{m}^{2}$ ) until 
the initiation of the crack at step 563, which caused a significant increase in $J$. It is recalled here that in this test the measured fields were reinitialized at step 565 to zoom in around the crack vicinity. At this step, the $J$-integral was also reset, and referred to $\Delta J$.

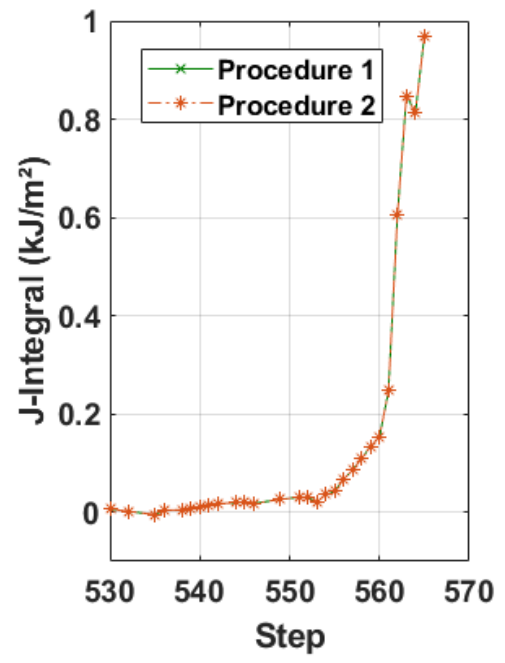

(A)

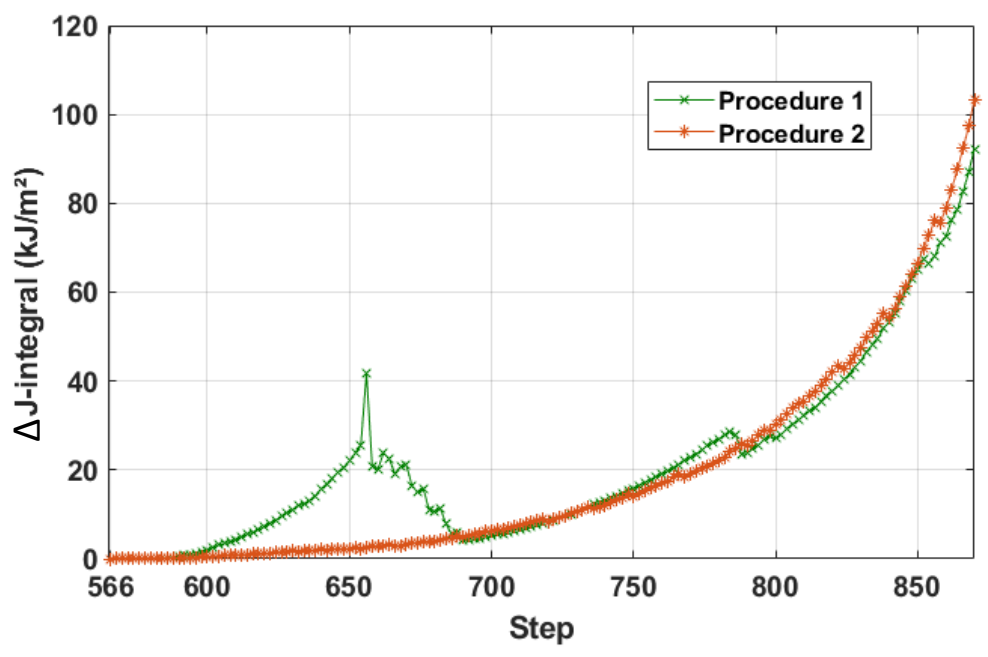

(B)

Figure 11: J-integral calculated by experimental method on both test parts with crack tip location given by the two proposed procedures; (A) test part $1,(B)$ test part2.

During the second part of the test, the value of $\Delta J$ increased continuously when using the crack tip location given by procedure 2 (Figure 11(B)). The curve took the expected shape of the variation of $\Delta J$ as a function of the load applied to the tested sample ${ }^{27,68}$. However, this was not the case using the position of the crack tip given by procedure 1. Results in Figure 11(B) (green curve) show a discrepancy appearing between steps 600 and 700 where the value of $J$ increased abnormally before suddenly falling off. This trend was due to bad positioning of the integration contour. During this period of time, the contour was not correctly placed around the crack tip but rather downstream by a significant amount (see Figure $\mathbf{8}$ between steps 600 and 700 ) and this is confirmed by the variation curve of $\Delta J$. This observation further proves that the results provided by procedure 1 cannot be trusted in that part of the analysis. Last, given the level of $J$ at the end of the first part (i.e., of the order of $1 \mathrm{~kJ} / \mathrm{m}^{2}$ ) and that observed in the second part (tens of $\mathrm{kJ} / \mathrm{m}^{2}$ ), the increment $\Delta J$ is very close to the total fracture energy.

It emerges from this analysis that the experimental method of calculating $J$ directly from kinematic fields measured by DIC can be applied to AM polymeric materials. Yet, its accuracy depends on integration contour location. It therefore required to be assisted by an accurate 
method of locating the crack tip around which this contour will be placed. In the next section, a comparison will be carried out between the results given by this method and those obtained by FE simulations for the same crack tip location.

\subsubsection{Experimental vs. FE evaluations of $J$}

The finite element model established to follow crack growth (procedure 2) calculated at each step the $J$-integral with the built-in procedure of the FE code ${ }^{38}$. The $J$-integral variation is compared in Figures 12 and 14 to those obtained by the experimental method based on DIC measurements. The results of the two parts of the test are analyzed separately. The crack tip position given by procedure 2 was considered as it was deemed more reliable than the strainbased procedure.

\section{- Test part 1}

A similarity is noted when comparing the results given by the experimental method and the FE computations. Both methods detect a very low level of $J$ in this part of the test but its variation was different. For the experimental method (procedure 1), $J$ remained equal to zero, and non-zero values were measured only a few instants before initiation, which was not the case for the FE-based procedure (2). The calculation gave nonzero values of $J$ early in the test even though the crack was physically nonexistent. Despite the very low values, it was interesting to investigate the possible causes of such differences. From the results of Figure 8, the initiation instant was defined as the first nonzero crack increment. The initiation time is depicted with the dashed box in Figure 12 and leads to a value of $J$ less than $1 \mathrm{~kJ} / \mathrm{m}^{2}$. 


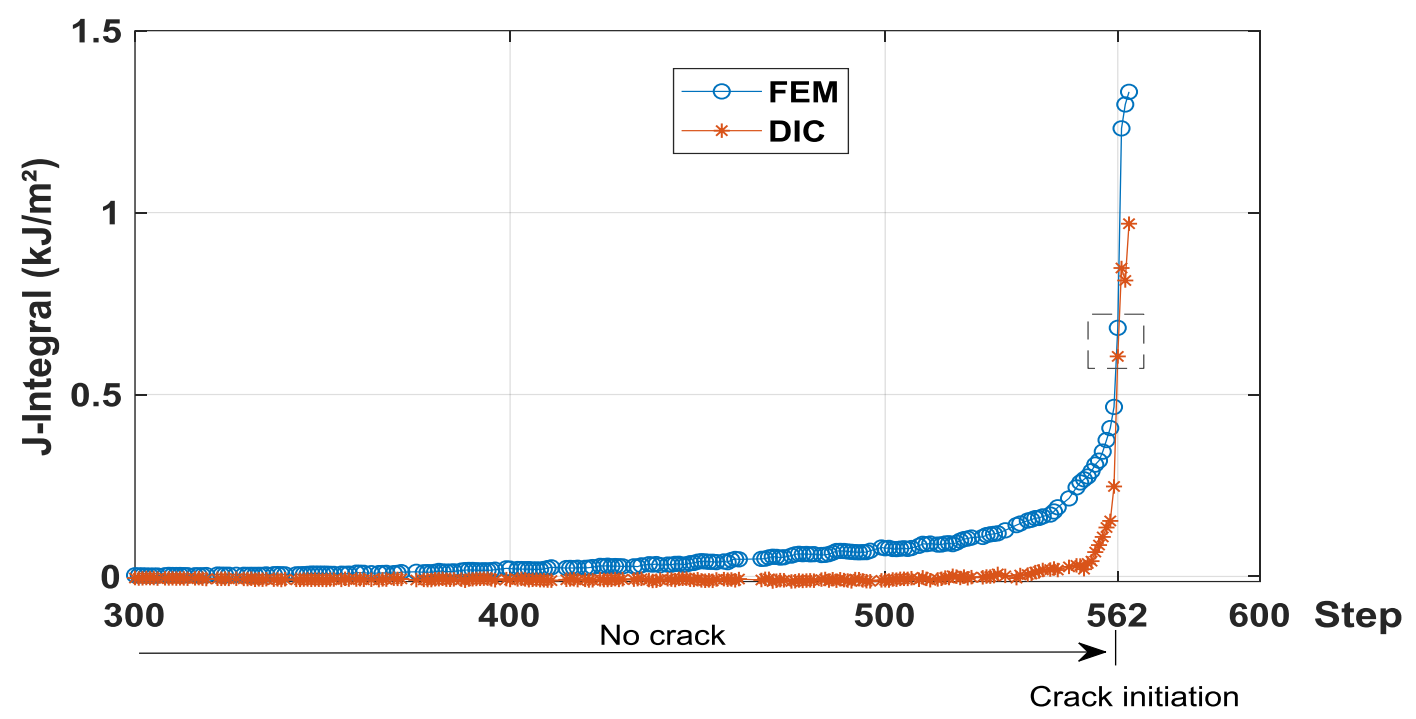

Figure 12: J-integral variation for the two procedures (experimental and FE). The dashed box depicts the estimated initiation instant.

In the finite element model established to find the crack tip position (procedure 2), the crack path was preset and at least one node was split. Each node on this path could be chosen as crack tip but only one node gave the minimum value of the displacement residual and it was the best approximation for crack tip location. When the modeled surface (i.e., the ROI chosen in DIC, see Figure 5) was free from any crack, the node for which the error will be minimal was that located on the left edge of the surface. The crack tip was thus located numerically on the edge of the ROI while physically it may lie outside the ROI. This shift induced an overestimation of the $J$-integral obtained numerically compared to the experimental route. To confirm this hypothesis, a second calculation was run using an elastic calculation driven by the measured boundary conditions with no crack. The identification error between the measured and computed displacements of the second FE simulation, $\delta$ (no crack), was calculated for each load step. Then, it was compared to the error of the initial model (with crack) by plotting the variation of the error difference

$$
\Delta=\sqrt{\frac{1}{n_{m}} \sum_{m=1}^{n_{m}}\left\|\mathbf{u}_{\text {meas }}\left(\mathbf{x}_{m}\right)-\mathbf{u}_{\text {comp }}\left(\mathbf{x}_{m}, \mathbf{x}_{c}=0\right)\right\|^{2}}-\sqrt{\frac{1}{n_{m}} \sum_{m=1}^{n_{m}} \| \mathbf{u}_{\text {meas }}\left(\mathbf{x}_{m}\right)-\mathbf{u}_{\text {comp }}\left(\mathbf{x}_{m}, \text { no crack }\right) \|^{2}}
$$

When $\Delta>0$, the solution with no crack is likelier than that with a small crack. Conversely, when $\Delta<0$, the solution with a crack is more trustworthy. For each step, the values of $\Delta$ are reported in Figure 13(A). At the beginning of the test, the error difference $\Delta$ was very small (i.e., less than the noise floor uncertainty). Then, the difference between the two models was 
more important, in favor of the model with no crack. From image 562 on, the initiation of the crack changed the trend, and therefore the model with no crack was less consistent with the experiment. This observation confirms that the choice of a point of the crack on the edge of the ROI caused an overestimation of $J$ compared to that obtained by the experimental method. The corrected $J$-curve is equal to zero up to image 562 (FEM' in Figure 13(B), and then it coincides with the previous results. This new estimation of the initiation time is consistent with what was obtained with the crack extension (Figure 12). It is worth noting that this additional analysis was conducted thanks to the results provided by the first procedure. Had it not been utilized, such additional study would not have been undertaken.

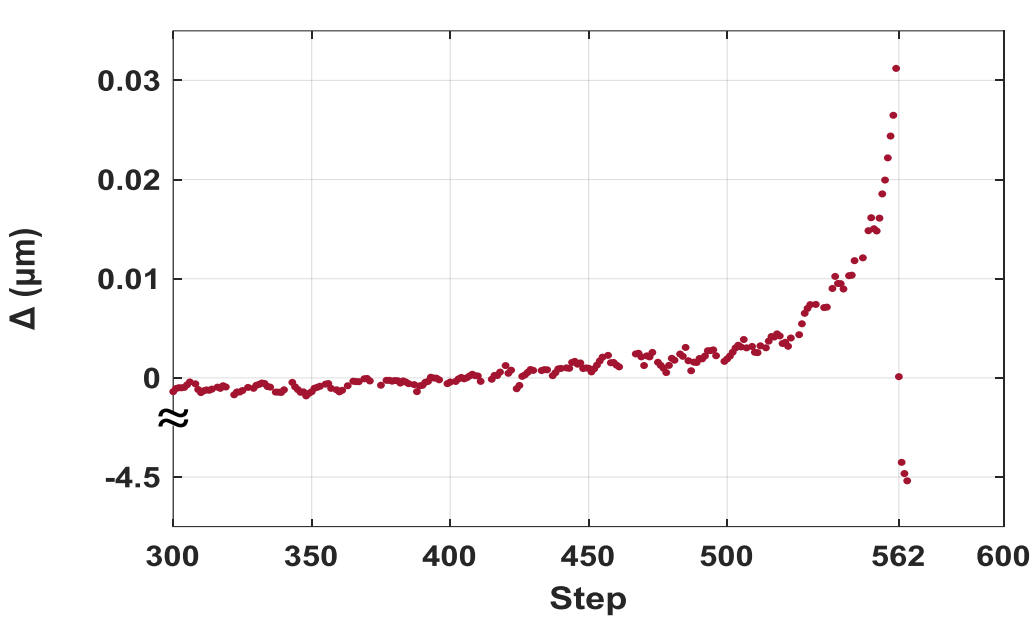

(A)

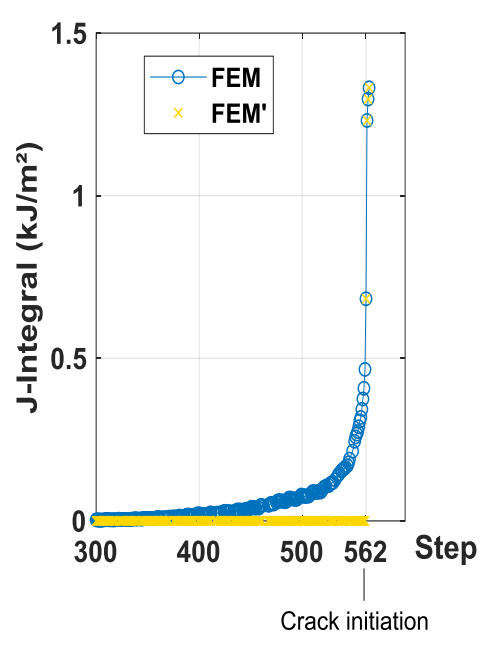

(B)

Figure 13: (A) Difference in identification error for the two models for the first part of the test. (B) J-integral obtained with procedure 2 when assuming the presence of the crack right from the beginning of the test (procedure 2) or only when $\Delta<0$ (procedure 2')

Figure 14 shows a comparison between the measured and computed longitudinal displacement fields for key load steps of the first part of the test by reporting the residual map. These maps are compared with the variation of $J$ as well as the identification error. The error maps show that the displacements were consistent with the experiment since the residuals were small (i.e., the mean value of $\delta$ was equal to $0.8 \mu \mathrm{m}$ which is only eight times the displacement uncertainty). This result means that the behavior of the material introduced in the model and the boundary conditions achieved a very good level of accuracy. From step 560 on, a process zone appeared and became more evident at step 562 in which the behavior of the material was 
no longer elastic close to the crack tip. In $3 \mathrm{~s}$, the welding joint between the filaments of the contour forming the notch was broken and the crack was open. The presence of the notch and the gradual loading created a process zone located at the crack tip (Figure 14, step 565). Plasticity was confined in the immediate vicinity of the crack tip, its impact on the $J$-integral remained minimal because the contour on which $J$ was calculated was sufficiently large.
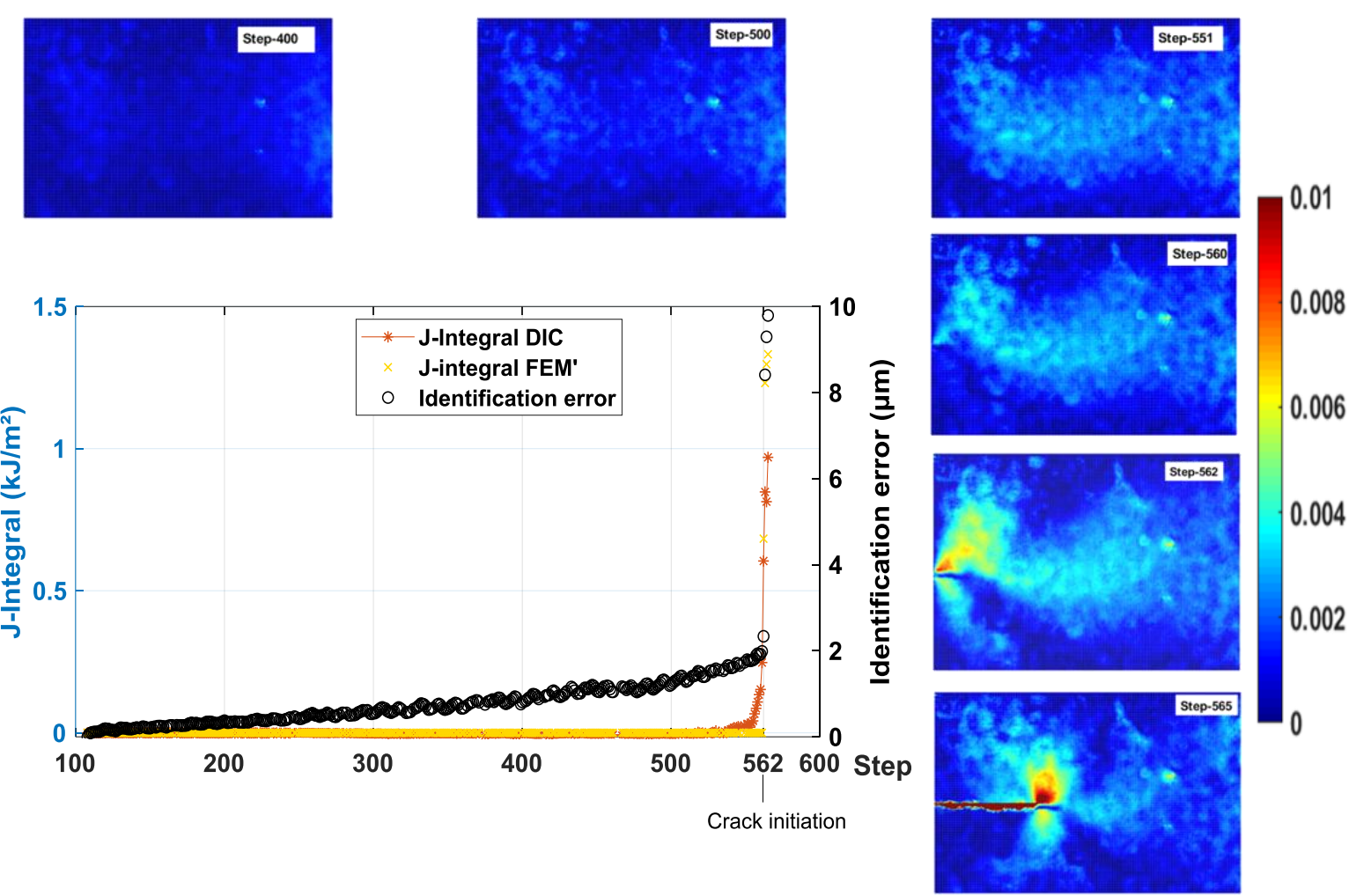

Figure 14: Residual displacement fields $(\mathrm{mm})$ for different load steps for the first part of the test

\subsubsection{Test part 2}

In the second part of the test, from the kinematic fields measured at the surface of the material the $J$-integral was calculated using both methods (Figure 15). Until step 772, both methods yielded almost the same levels of $J$ (Root Mean Squared error $\left.=0.46 \mathrm{~kJ} / \mathrm{m}^{2}\right)$. From step 772 on, the results diverge, namely, the experimental procedure gave higher values of $J$ than those computed by the FE-based procedure. In section 2, when analyzing identification error variations in the second part of the test, a first assumption was made regarding the origin of the offset between experimental and computed fields (i.e., nonlinearities in the process zone and 3D effects close to the crack front). For higher levels, plastic deformations and damage 
appeared elsewhere than around the crack tip (Figure 3) so that the error between measured and computed displacements and strains increased, which led to the $J$-integral offset.

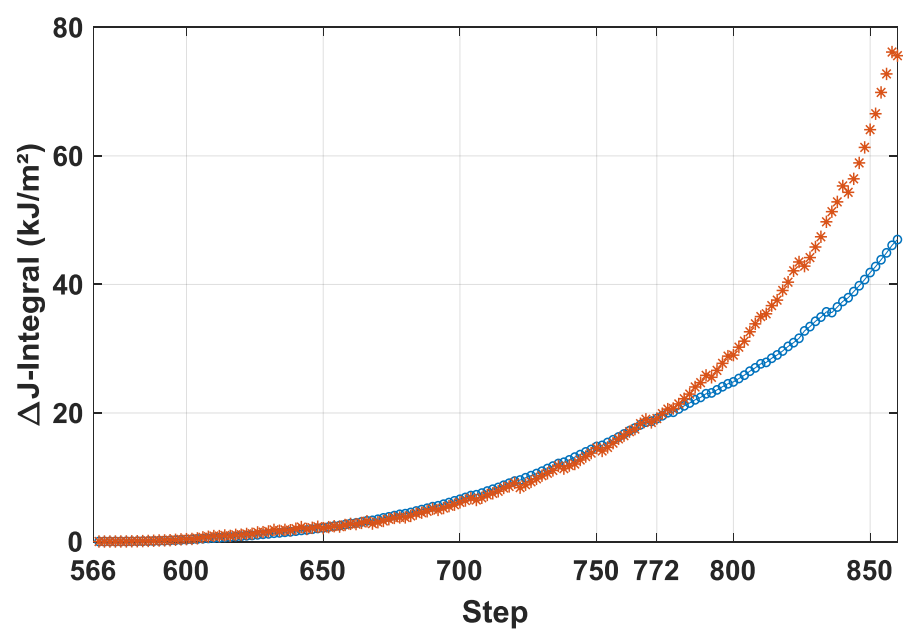

(A)

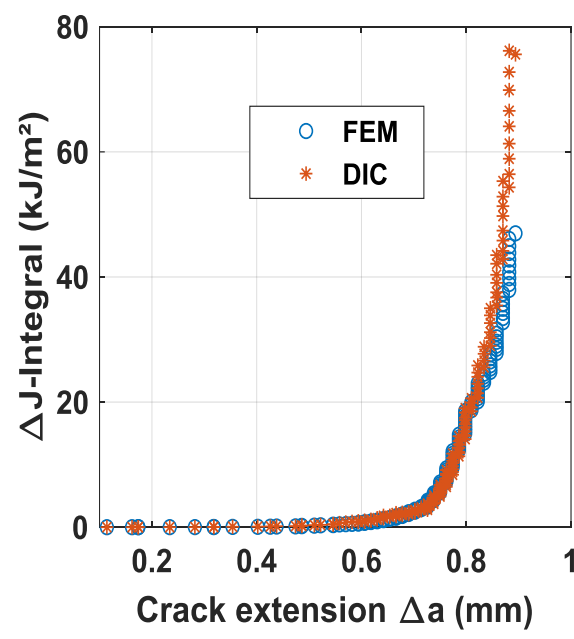

(B)

Figure 15: (A) J-integral changes using both procedures with the same crack tip location.

(B) Corresponding $\Delta J-R$ curves.

Residual longitudinal displacements maps reported in Figure 16 evidence these effects. For relatively low loads (e.g. step 650), the FE model described rather well the material behavior and the identification error in displacement did not exceed $13 \mu \mathrm{m}$. It is worth noting that along the propagation path one additional source of error is related to DIC as the corresponding measurements may be biased because of displacement discontinuities induced by crack. The evaluation of the $J$-integral by both methods yielded almost the same level. From step 772 on, the plastic deformation extended to locations other than the crack tip vicinity, which made the FE model not very precise because it did not consider the plastic behavior. This is also true for the experimental procedure in which the stress levels were overestimated since they were computed by using the total strains evaluated via DIC. In the FE model, the computed value of $J$ related only to the main crack whereas in the experimental method it included nonlinear deformations that appeared elsewhere in the specimen (Figure 3). 

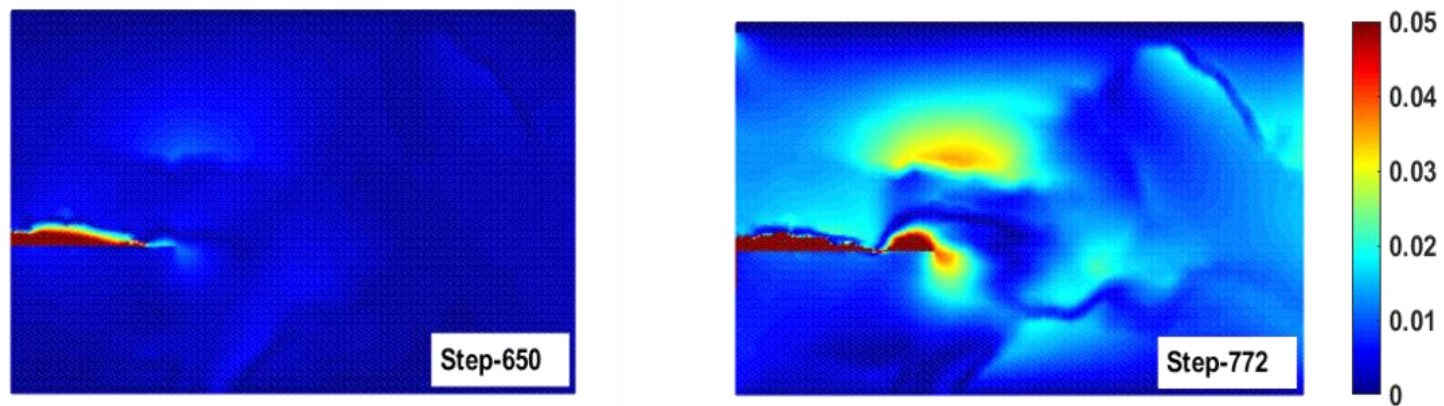

Figure 16: Residual longitudinal displacement fields $(\mathrm{mm})$ for two steps of the second part of the test.

\section{CONCLUSION}

In order to investigate the fracture behavior of AM ABS, two methods for evaluating the $J$ integral and crack growth were examined. It was shown that the $J$-integral could be obtained accurately by both methods during most of the propagation regime. The FE-based method showed very high robustness to accurately locate the crack tip, and the $J$-integral calculation was based on local DIC measurements. The analysis of the initiation regime showed that the experimental procedure could better capture the early initiation steps. It allowed the numerical procedure to be supplemented by an additional analysis with no crack. From such analysis, the initiation time was shown to be fully consistent with its estimate based on the crack advance. In the present case, both methods were needed to accurately quantify crack initiation and propagation.

The investigated procedures were shown to be well adapted to polymeric 3D printed materials and gave access to micrometer scales that have an important effect on the mechanical properties of such materials. The applicability of these methods is not limited to the identification of fracture properties of AM polymer parts but can also be extended to the determination of other mechanical properties. The FE-based method applied in this study makes it possible to locally check the validity of the elastic properties (as shown herein) or even enrich the model to describe the nonlinear behavior in the process zone.

\section{ACKNOWLEDGMENTS}

This work was supported by Region Grand Est (France) via the funding NANO-FAB (18-GES027) Soutien aux jeunes chercheurs. 


\section{STATEMENT OF CONTRIBUTIONS}

M.A. BOUAZIZ, J. MARAE DJOUDA and F. HILD conceived the presented idea. J. GARDAN and M. ZOUAOUI manufactured the samples.J. MARAE DJOUDA carried out the experiment. M.A. BOUAZIZ processed the experimental data, performed the analysis, drafted the manuscript and designed the figures. F. HILD and J. MARAE DJOUDA supervised and guided the investigations and contributed to the development of the method. They also aided M.A. BOUAZIZ in interpreting the results and worked on the manuscript. All authors commented on the manuscript.

\section{DATA AVAILABILITY STATEMENT}

The data that support the findings of this study are available from the corresponding author upon reasonable request. 


\section{REFERENCES}

1 Attaran M. The rise of 3-D printing: The advantages of additive manufacturing over traditional manufacturing. Bus Horiz. 2017;60: 677-688.

2 Tofail SAM, Koumoulos EP, Bandyopadhyay A, Bose S, O’Donoghue L, Charitidis C. Additive manufacturing: scientific and technological challenges, market uptake and opportunities. Mater Today. 2018;21: 22-37.

Ivanova O, Williams C, Campbell T. Additive manufacturing (AM) and nanotechnology: Promises and challenges. Rapid Prototyp J. 2013;19: 353-364.

Gardan J. Additive manufacturing technologies: State of the art and trends. Int J Prod Res. 2015;7543: 149-168.

Turner BN, Strong R, Gold SA. A review of melt extrusion additive manufacturing processes: I. Process design and modeling. Rapid Prototyp J. 2014;20: 192-204.

Durgun I, Ertan R. Experimental investigation of FDM process for improvement of mechanical properties and production cost. Rapid Prototyp J. 2014;20: 228-235.

7 Balderrama-Armendariz CO, MacDonald E, Espalin D, Cortes-Saenz D, Wicker R, Maldonado-Macias A. Torsion analysis of the anisotropic behavior of FDM technology. Int J Adv Manuf Technol. 2018;96: 307-317.

8 Sood AK, Ohdar RK, Mahapatra SS. Experimental investigation and empirical modelling of FDM process for compressive strength improvement. $J$ Adv Res. 2012;3: 81-90.

9 Vairis A, Petousis M, Vidakis N, Savvakis K. On the Strain Rate Sensitivity of Abs and Abs Plus Fused Deposition Modeling Parts. J Mater Eng Perform. 2016;25: 3558-3565.

10 Sun Q, Rizvi GM, Bellehumeur CT, Gu P. Effect of processing conditions on the bonding quality of FDM polymer filaments. Rapid Prototyp J. 2008;14: 72-80.

11 Ahn SH, Montero M, Odell D, Roundy S, Wright PK. Anisotropic Material Properties of Fused Deposition Modeling ABS. Vol 8.2002.

12 Cantrell JT, Rohde S, Damiani D, et al. Experimental characterization of the mechanical properties of 3D-printed ABS and polycarbonate parts. Rapid Prototyp J. 2017;23: 811824.

13 Rezayat H, Zhao W, Siriruk A, Penumadu D, Babu SS. Structure - mechanical property relationship in fused deposition modelling. Mater Sci Technol. 2015;31(8): 895-903.

14 Chacón JM, Caminero MA, García-Plaza E, Núñez PJ. Additive manufacturing of PLA structures using fused deposition modelling: Effect of process parameters on mechanical properties and their optimal selection. Mater Des. 2017;124: 143-157.

15 Cuan-Urquizo E, Barocio E, Tejada-Ortigoza V, Pipes RB, Rodriguez CA, RomanFlores A. Characterization of the mechanical properties of FFF structures and materials: A review on the experimental, computational and theoretical approaches. Materials (Basel). 2019;16.

16 Zaldivar RJ, Witkin DB, McLouth T, Patel DN, Schmitt K, Nokes JP. Influence of processing and orientation print effects on the mechanical and thermal behavior of 3DPrinted ULTEM ® 9085 Material. Addit Manuf. 2017;13: 71-80.

17 Hart KR, Wetzel ED. Fracture behavior of additively manufactured acrylonitrile 
butadiene styrene (ABS) materials. Eng Fract Mech. 2017;177: 1-13.

18 Aliheidari N, Christ J, Tripuraneni R, Nadimpalli S, Ameli A. Interlayer adhesion and fracture resistance of polymers printed through melt extrusion additive manufacturing process. Mater Des. 2018;156: 351-361.

19 Aliheidari N, Tripuraneni R, Ameli A, Nadimpalli S. Fracture resistance measurement of fused deposition modeling 3D printed polymers. Polym Test. 2017;60: 94-101.

20 McLouth TD, Severino J V., Adams PM, Patel DN, Zaldivar RJ. The impact of print orientation and raster pattern on fracture toughness in additively manufactured ABS. Addit Manuf. 2017;18: 103-109.

21 Brugo T, Palazzetti R, Ciric-Kostic S, Yan XT, Minak G, Zucchelli A. Fracture mechanics of laser sintered cracked polyamide for a new method to induce cracks by additive manufacturing. Polym Test. 2016;50: 301-308.

22 Li J, Yang S, Li D, Chalivendra V. Numerical and experimental studies of additively manufactured polymers for enhanced fracture properties. Eng Fract Mech. 2018;204: $557-569$.

23 Rice JR. A Path Independent Integral and the Approximate Analysis of Strain Concentration by Notches and Cracks. J Appl Mech. 1968;35: 379.

24 Catalanotti G, Camanho PP, Xavier J, Dávila CG, Marques AT. Measurement of resistance curves in the longitudinal failure of composites using digital image correlation. Compos Sci Technol. 2010;70: 1986-1993.

25 Becker TH, Mostafavi M, Tait RB, Marrow TJ. An approach to calculate the J-integral by digital image correlation displacement field measurement. Fatigue Fract Eng Mater Struct. 2012;35: 971-984.

26 Becker TH, Marrow TJ, Tait RB. Damage, crack growth and fracture characteristics of nuclear grade graphite using the Double Torsion technique. J Nucl Mater. 2011;414: 32-43.

27 Yoneyama S, Arikawa S, Kusayanagi S, Hazumi K. Evaluating J-integral from displacement fields measured by digital image correlation. Strain. 2014;50: 147-160.

28 J. W. Hutchinson. Singular Behaviour at The End of a Tensile Crack in a Hardening Materail. J Mech Phys Solids. 1978;16: 13-31.

29 Lanzillotti P, Gardan J, Makke A, Recho N. Enhancement of fracture toughness under mixed mode loading of ABS specimens produced by 3D printing. Rapid Prototyp J. 2019;25: 679-689.

30 Nishioka T, Ikegita H, Tamai K, Kobayashi N. An Incremental Variational Principle Minimizing Experimental Measurement Errors and Its Application to an Intelligent Hybrid Experimental-Numerical Method. Case of Nonlinear Elastic-Plastic Deformation Field. JSME Int J Ser A. 2001;44: 71-81.

31 Hareesh T V., Chiang FP. Integrated experimental-finite element approach for studying elasto-plastic crack-tip fields. Eng Fract Mech. 1988;31: 451-461.

32 Mathieu F, Aimedieu P, Guimard JM, Hild F. Identification of interlaminar fracture properties of a composite laminate using local full-field kinematic measurements and finite element simulations. Compos Part A Appl Sci Manuf. 2013;49: 203-213.

33 Barhli SM, Mostafavi M, Cinar AF, Hollis D, Marrow TJ. J-Integral Calculation by 
Finite Element Processing of Measured Full-Field Surface Displacements. Exp Mech. 2017;57: 997-1009.

34 Isaac JP, Dondeti S, Tippur H V. Crack initiation and growth in additively printed ABS: Effect of print architecture studied using DIC. Addit Manuf. 2020;36: 101536.

35 Marae-Djouda J, Gallittelli D, Zouaoui M, et al. Local scale fracture characterization of an advanced structured material manufactured by fused deposition modeling in 3D printing. Frat ed Integrita Strutt. 2020;14: 534-540.

36 Marae-Djouda J, Bouaziz MA, Zouaoui M, et al. Experimental approach for microscale mechanical characterization of polymeric structured materials obtained by additive manufacturing. Polym Test. May 2020: 106634.

37 SIMULIA. ABAQUS/Standard Version 6.18 Analysis User’s Manual. 2018.

38 Simulia. Contour integral evaluation (Section 11.4.2). Abaqus Analysis User's Manual.

39 Brocks W, Scheider I. Numerical Aspects of the Path-Dependenceof the J-Integral in Incremental Plasticity How to Calculate Reliable J-Values in FE Analyses. Int J Fatigue. 2001: 1-33.

40 ASTM-E1820-11. Standard test method for measurement of fracture toughness. In: ASTM, Annual Book of Standards 3. ; 2011.

41 ASTM-6068. Standard Test Method for Determining J-R Curves of Plastic Materials. ASTM Stand Test Method. 2013;i: 1-8.

42 Bruck HA, McNeill SR, Sutton MA, Peters WH. Digital image correlation using Newton-Raphson method of partial differential correction. Exp Mech. 1989;29: 261267.

43 Forquin P, Rota L, Charles Y, Hild F. A method to determine the macroscopic toughness scatter of brittle materials. Int J Fract. 2004;125: 171-187.

44 M. Sutton, W. Zhao, S. McNeill, J. Helm, R. Piascik and WR. Local crack closure measurements: Development of a measurement system using computer vision and a farfield microscope. Adv fatigue crack Clos Meas Anal Second Vol ASTM Int. 1999.

45 Blaber J, Adair B, Antoniou A. Ncorr: Open-Source 2D Digital Image Correlation Matlab Software. Exp Mech. 2015;55: 1105-1122.

46 Pan B. Full-field strain measurement using a two-dimensional Savitzky-Golay digital differentiator in digital image correlation. Opt Eng. 2007;46: 33601.

47 Zouaoui M, Gardan J, Lafon P, Labergere C, Makke A, Recho N. Transverse Isotropic Behavior Identification using Digital Image Correlation of a Pre-structured Material Manufactured by 3D Printing. Procedia Struct Integr. 2020;28: 978-985.

48 Roux S, Réthoré J, Hild F. Digital image correlation and fracture: An advanced technique for estimating stress intensity factors of 2D and 3D cracks. $J$ Phys D Appl Phys. 2009;42.

49 Beevers C. Advances in crack length measurement. Eng Mater Advis Serv. 1982.

50 Hild F, Roux S. Digital image correlation: From displacement measurement to identification of elastic properties - A review. Strain. 2006;42: 69-80.

51 Hamam R, Hild F, Roux S. Stress intensity factor gauging by digital image correlation: Application in cyclic fatigue. Strain. 2007;43: 181-192. 
52 Réthoré J, Roux S, Hild F. An extended and integrated digital image correlation technique applied to the analysis of fractured samples: The equilibrium gap method as a mechanical filter. Eur J Comput Mech. 2009;18: 285-306.

53 Mathieu F, Hild F, Roux S. Image-based identification procedure of a crack propagation law. Eng Fract Mech. 2013;103: 48-59.

54 Nguyen TL, Hall SA, Vacher P, Viggiani G. Fracture mechanisms in soft rock: Identification and quantification of evolving displacement discontinuities by extended digital image correlation. Tectonophysics. 2011;503: 117-128.

55 Vargas R, Neggers J, Canto RB, Rodrigues JA, Hild F. Comparison of two full-field identification methods for the wedge splitting test on a refractory. $J$ Eur Ceram Soc. 2018;38: 5569-5579.

56 Grédiac M, Hild F. Full-field measurements and identification in solid mechanics. 2012.

57 Zouaoui M, Labergere C, Gardan J, et al. Numerical prediction of 3d printed specimens based on a strengthening method of fracture toughness. Procedia CIRP. 2019;81: 4044.

58 Vargas R, Tsitova A, Bernachy-Barbe F, Bary B, Canto RB, Hild F. On the identification of cohesive zone model for curved crack in mortar. Strain. 2020;56.

59 Hild F, Bouterf A, Roux S, Measurements D, Physical F. Damage Measurements via DIC François Hild, Amine Bouterf, Stéphane Roux To cite this version : HAL Id : hal01166736 Damage Measurements via DIC From Physical to Mechanical Damage. Int J Fract. 2015;191: 77-105.

60 Somireddy M, Czekanski A. Mechanical Characterization of Additively Manufactured Parts by FE Modeling of Mesostructure. J Manuf Mater Process. 2017;1: 18.

61 Casavola C, Cazzato A, Moramarco V, Pappalettere C. Orthotropic mechanical properties of fused deposition modelling parts described by classical laminate theory. Mater Des. 2016;90: 453-458.

62 Zhao Y, Chen Y, Zhou Y. Novel mechanical models of tensile strength and elastic property of FDM AM PLA materials: Experimental and theoretical analyses. Mater Des. 2019;181: 108089.

63 Réthoré J, Gravouil A, Morestin F, Combescure A. Estimation of mixed-mode stress intensity factors using digital image correlation and an interaction integral. Int J Fract. 2005;132: 65-79.

64 Réthoré J, Roux S, Hild F. Noise-robust stress intensity factor determination from kinematic field measurements. Eng Fract Mech. 2008;75: 3763-3781.

65 Réthoré J, Roux S, Hild F. Optimal and noise-robust extraction of Fracture Mechanics parameters from kinematic measurements. Eng Fract Mech. 2011;78: 1827-1845.

66 Courtin S, Gardin C, Bézine G, Ben Hadj Hamouda H. Advantages of the J-integral approach for calculating stress intensity factors when using the commercial finite element software ABAQUS. Eng Fract Mech. 2005;72: 2174-2185.

67 Bouaziz MA, Guidara MA, Schmitt C, Hadj-Taïeb E, Azari Z, Dmytrakh I. Structural integrity analysis of HDPE pipes for water supplying network. Fatigue Fract Eng Mater Struct. 2019;42: 792-804.

68 Vavrik D, Jandejsek I. Experimental evaluation of contour J integral and energy 
dissipated in the fracture process zone. Eng Fract Mech. 2014;129: 14-25. 